\title{
Libras na formação médica: possibilidade de quebra da barreira comunicativa e melhora na relação médico-paciente surdo
}

\author{
Brasilian Sign Language (Libras) on medical education: possibility of improvement \\ on communicative barriers and death patient-physician relationship
}

\author{
Andrezza Resende Dias ${ }^{1}$, Cinthya Rodrigues Coutinho', \\ Deborah Rocha Gaspar ${ }^{1}$, Letícia Moeller ${ }^{1}$, Marcelo Mamede ${ }^{2}$
}

Dias AR, Coutinho CR, Gaspar DR, Letícia Moeller'1, Mamede M. Libras na formação médica: possibilidade de quebra da barreira comunicativa e melhora na relação médico-paciente surdo / Brasilian Sign Language (Libras) on medical education: possibility of improvement on communicative barriers and death patient-physician relationship. Rev Med (São Paulo). 2017 out.-dez.;96(4):209-14.

RESUMO: INTRODUÇÃO: Mudanças curriculares para a graduação em Medicina incluem o desenvolvimento de habilidades de comunicação na graduação do aluno. $\mathrm{O}$ conhecimento da Língua Brasileira de Sinais (Libras) pelo médico visa romper barreiras comunicativas com os pacientes surdos e é um bom método para se obter escuta qualificada e excelência do cuidado em saúde. OBJETIVO: Avaliar o contingente de médicos recém-formados pela Universidade Federal de Minas Gerais (UFMG) que domina a Libras. MÉTODOS: Entrevista aplicada aos alunos do $12^{\circ}$ período do curso de Medicina da UFMG, utilizando um questionário online na plataforma Google Forms. RESULTADOS: Foram entrevistados 102 alunos. Nenhum deles tinha domínio sobre a língua e apenas $7 \%$ possuíam alguma habilidade. Desses, o que os motivaram a aprender Libras foi a proximidade com deficientes auditivos, o interesse em romper a barreira comunicativa entre profissionais de saúde e surdos ou a curiosidade. O meio utilizado para aprender Libras foi variado. Um quarto dos alunos não sabia da existência da disciplina optativa "Fundamentos de Libras" disponibilizada pela UFMG e, dentre os que sabiam, apenas três fizeram a disciplina. Para atender um deficiente auditivo, mais da metade dos alunos disseram que escreveria, desenharia e/ou faria mímicas, e 8 deles não saberiam o que fazer. Dentre os que possuem alguma habilidade na Libras, todos utilizariam a língua mesmo que de maneira limitada. Quase $80 \%$ dos entrevistados acreditam que é importante para a formação médica saber se comunicar com surdos por meio da Libras. CONCLUSÃO: Existe uma barreira comunicativa entre os estudantes de medicina recém-formados da UFMG e os surdos que utilizam a Libras. Tal estudo mostra, portanto, a noção da grandiosidade desse impasse, indicando a necessidade de iniciativas que preconizem pesquisas que possam divulgar as situações problemas e, posteriormente, tentar resolvê-las.

Descritores: Linguagens de sinais; Comunicação; Barreiras de comunicação; Linguagem; Pessoas com deficiência auditiva; Pessoal de saúde/educação; Estudantes de medicina; Educação médica.

ABSTRACT: INTRODUCTION: Curricular changes for Medical graduation includes the development of communication skills of the medical student. The knowledge of the Brazilian Sign Language (Libras) by the physician aims to break communicative barriers with deaf patients and is a good method to obtain qualified listening and excellence in health care. OBJECTIVE: To evaluate the contingent of doctors recently graduated from the Federal University of Minas Gerais (UFMG) who dominate Libras. METHODS: Interview applied to the students of the 12 th period of the Medical School of UFMG, using an online questionnaire on the Google Forms platform. RESULTS: A total of 102 students were interviewed. None of them had mastery over the language and only $7 \%$ had some skill. Of those, what motivated them to learn Libras was the proximity to deaf people, the interest on breaking the communicative barrier between health professionals and the deaf or the curiosity. The way used to learn Libras was varied. A quarter of students did not know about the discipline "Fundamentals of the Brasilian Sign Language (Libras)" offered

1. Universidade Federal de Minas Gerais - UFMG, Faculdade de Medicina, Belo Horizonte, MG, BR. E-mails: andrezzardias@gmail. com, cinthyarodriguescoutinho@yahoo.com.br, deborahrgaspar@hotmail.com, moellerleticia@gmail.com.

2. Universidade Federal de Minas Gerais - UFMG, Faculdade de Medicina, Departamento de Anatomia e Imagem, Belo Horizonte, MG, BR.

Endereço para correspondência: Marcelo Mamede. Departamento Anatomia e Imagem. Faculdade de Medicina - UFMG. Av. Prof. Alfredo Balena, 190 - Sala 175. Centro - Belo Horizonte, MG, BR. CEP: 30.130-100. Email: mamede.mm@gmail.com. 
by UFMG and, among those who knew, only three of them took the discipline. In order to attend a deaf patient, more than half of the students said they would write, design, and/or mimic, and 8 of them did not know what they would do. Among those with some Libras ability, all would use the language even in a limited way. Almost $80 \%$ of the interviewed believe that it is important for the medical education to know how to communicate with the deaf through Libras. CONCLUSION: There is a communicative barrier

\section{INTRODUÇÃO}

Problemas de comunicação interpessoal estão presentes em todo o sistema de saúde brasileiro e tornam-se mais significantes quando englobam barreiras culturais e de linguagem. Assim como estrangeiros e outros grupos minoritários linguísticos e culturais existentes no Brasil, a comunidade surda, que utiliza a Língua Brasileira de Sinais (Libras) como meio de comunicação, encontra obstáculos no acesso aos serviços de saúde ${ }^{1}$. Essas semelhanças incluem o acesso limitado à comunicação baseada na língua portuguesa, no contato infrequente com clínicos familiarizados com a Libras e a cultura do paciente surdo e na experiência desafiadora de trabalhar com familiares e amigos como intérpretes.

Segundo o último Censo, realizado em 2010, pelo Instituto Brasileiro de Geografia e Estatística (IBGE) ${ }^{2}$, existem no Brasil cerca de mais de 9,7 milhões de pessoas com deficiência auditiva. Desse total, quase 350 mil são totalmente surdas. Ademais, a perda da audição é a terceira maior causa de deficiência que atinge a população brasileira e pode estar relacionada a doenças ou acidentes.

É notório que nem todos os deficientes auditivos utilizam a Libras para se comunicar. Assim como nos Estados Unidos (EUA) ${ }^{3}$, o censo não recolhe informações sobre a quantidade de deficientes auditivos que utilizam a língua gestual no Brasil, sendo difícil mensurar, dessa forma, a porcentagem da população que a utiliza. Todavia, a escolha das estratégias de comunicação que serão ensinadas e trabalhadas com os deficientes auditivos dependem do tipo de educação escolar, dos antecedentes sociais e culturais e do idioma primário escolhido, levando em conta o tipo de categoria da perda auditiva deste indivíduo ${ }^{4}$. Contudo, sabe-se, segundo estudos sobre comunicação de surdos e deficientes auditivos nos EUA, que para muitas pessoas surdas, particularmente aquelas que foram ensurdecidas antes da idade de três anos, a língua de sinal é o principal meio de comunicação ${ }^{3}$.

Diante desse contexto, percebe-se que uma efetiva comunicação com pacientes surdos é primordial na área da saúde, isto porque comunicar é uma ferramenta importante para os médicos no diagnóstico de doenças e no desenvolvimento da relação médico-paciente ${ }^{3}$. Dessa forma, a chave para o sucesso da comunicação com pessoas com deficiência auditiva é a capacidade de se adaptar às necessidades da situação do próprio paciente. Entretanto, nota-se que um dos maiores fatores between the doctors recently graduated from UFMG and deaf who use Libras. The study shows, a notion of the grandiosity of this impasse, indicating a need for initiatives that advocate research that reveal the problematic situations, and then, try to solve them.

Keywords: Sign language; Communication; Communication Communication Barriers; Language; Persons with hearing impairments; Health personnel/education; Students, medical; Education, medical.

que interferem na qualidade e adequação da assistência prestada pelos profissionais da saúde aos pacientes surdos, é, exatamente, a não consciência de quem é a pessoa surda e seu contexto social e cultural, associado à inabilidade de uma comunicação não verbal ${ }^{5,6,7}$.

Apesar de existirem barreiras que dificultam a interação entre surdos e ouvintes, há também avanços educacionais, linguísticos, tecnológicos e até comportamentais que permitem, atualmente, uma melhor integração deste grupo à sociedade ${ }^{4}$. Devido à sua importância para o país, foram sancionados a Lei $n^{\circ} 10.436$, de 24 de abril de 2002, que reconhece oficialmente a Libras como meio legal de comunicação e expressão ${ }^{8}$, e o decreto 5.626 de 2005, que, além de regulamentar a lei supracitada, determina a obrigatoriedade do ensino da Libras nos cursos de formação para o exercício do magistério ou licenciatura e aos demais cursos de educação superior e profissional. $\mathrm{O}$ decreto afirma que a disciplina também deverá ser ofertada de forma eletiva ${ }^{9}$. Nesta linha de ação, o Ministério da Saúde elaborou em 2006 o manual intitulado "A Pessoa com Deficiência e o Sistema Único de Saúde", destinado aos médicos, enfermeiros e outros profissionais das equipes de saúde, no qual propõe a inclusão social das pessoas com deficiência como meta mais abrangente ${ }^{10}$.

Contudo, mesmo havendo medidas e propostas que tentam melhorar a inclusão dessas pessoas com deficiência auditiva nos contextos sociais brasileiros, ainda se vê muito despreparo com tais indivíduos, principalmente na área médica, acarretando mazelas e descuido dessa população. Em um estudo sobre os desafios da prática do acolhimento de surdos na atenção primária em um Centro de Saúde do Rio de Janeiro, durante as entrevistas, ficou evidente que os profissionais de saúde sentem-se desconfortáveis ao atender pessoas surdas. Eles, por sua vez, referiram o sentimento de ansiedade e de angústia como fatores presentes durante os atendimentos e alegaram que esses sentimentos surgem porque se sentem despreparados para um atendimento não comum $^{11}$.

Dessa forma, a remoção de barreiras de comunicação no ambiente clínico é um primeiro passo crítico para encorajar pacientes surdos e com deficiência auditiva a usar plenamente os cuidados de saúde disponíveis. Uma comunicação mais clara no contexto clínico traduz-se num sistema de saúde mais acessível para este grupo e relações mais fortes entre o paciente e o provedor. Essas melhorias resultarão em maior uso de medicina preventiva, melhor compreensão das doenças e adesão ao tratamento e maior 
satisfação do paciente ${ }^{12}$

Levando isso em consideração, para averiguar se os graduados em medicina têm as habilidades necessárias para se comunicar com pessoas surdas ou com deficiência auditiva através de uma das estratégias comunicacionais dos surdos, a Libras, deve-se, como primeiro passo, avaliar os currículos escolares e o conhecimento acadêmico dos alunos de medicina ${ }^{13}$. Dessa forma, o presente estudo objetivou analisar o conhecimento linguístico de Libras dos estudantes do décimo segundo período de Medicina da Universidade Federal de Minas Gerais (UFMG), buscando identificar deficiências comunicacionais na preparação desses acadêmicos e quais são suas impressões sobre o tema.

\section{METODOLOGIA}

Foi feito um estudo de caráter descritivo analítico, com abordagem quantitativa e qualitativa, que utilizou para coleta de dados uma entrevista com alunos do $12^{\circ}$ período da UFMG do primeiro semestre de 2016. Foram entrevistados 102 alunos de 146 alunos matriculados. Os alunos do $12^{\circ}$ período foram escolhidos, pois são alunos prestes a se formar em Medicina, o que permite avaliar fielmente se o aluno será um profissional capaz de se comunicar através da Libras. $\mathrm{O}$ instrumento utilizado para a coleta de dados foi uma entrevista online na plataforma Google Forms, contendo 7 questões quantitativas que avaliaram: da Libras;

1) Se o aluno sabe se comunicar com surdos através

2) O que levou o aluno a aprender Libras (caso a resposta 1 fosse sim);

3) Onde ele aprendeu e estudou a língua de sinais (caso a resposta 1 fosse sim);

4) Se ele fez a disciplina optativa "Fundamentos de Libras" oferecida pela UFMG;

5) Se ele sabia que existia essa a disciplina "Fundamentos de Libras" como disciplina optativa no currículo da UFMG;

6) Se acredita ser importante para a formação médica saber se comunicar com deficientes auditivos através da Libras; e

7) O que ele faria se, depois de formado, um surdo fosse ao consultório dele e só utilizasse a língua de sinais.

Os dados foram arquivados e analisados pelo programa estatístico Excel (versão 2010), e a análise de dados consistiu na construção de tabelas de distribuição de frequências.

Além disso, uma questão qualitativa permitiu avaliar se o aluno "acredita" ou "não acredita" ser importante para a formação médica saber se comunicar com deficientes auditivos através da Libras, questão através da qual pode-se estabelecer 3 perfis de respostas de acordo com conceitoschave frequentes:

Perfil 1. Acreditam ser importante e essencial saber Libras (conceitos-chave: inclusão, vínculo, boa relação médico-paciente, comunicação efetiva, atendimento universal);

Perfil 2. Acreditam ser importante, mas não essencial saber Libras (Conceitos-chave: comunicação possível sem a língua de sinais, situações raras de surdez, formas de comunicação alternativas);

Perfil 3. Não acreditam ser importante saber Libras (Conceitos-chave: irrelevante, raros casos de surdez, meios de comunicação alternativos, poucos médicos capacitados são suficientes).

\section{RESULTADOS}

Os resultados obtidos na pesquisa se basearam nas respostas dos 101 alunos do $12^{\circ}$ período de medicina da UFMG, visto que o participante 18 foi excluído da análise por suas respostas incoerentes.

No presente estudo, observou-se que a grande maioria dos alunos prestes a se formar em Medicina não sabem Libras e poucos possuem alguma habilidade. (Tabela 1). Dentre os sete que possuem alguma habilidade, foi questionado o que os levaram a aprender Libras: três responderam que foi por curiosidade, dois pela proximidade com deficientes auditivos (família, amigos, outros) e outros dois para romper a barreira comunicativa existente entre profissionais da saúde e aqueles que utilizam Libras.

Tabela 1. Perguntas e Respostas sobre a comunicação por meio da Libras

\begin{tabular}{l|c|c}
\hline $\begin{array}{l}\text { Perguntas e } \\
\text { Respostas }\end{array}$ & Frequência & \% \\
\hline \multicolumn{3}{|c}{ Você sabe se comunicar com surdos por meio da Libras? } \\
\hline Sim & 0 & 0,0 \\
\hline Não & 94 & 93,1 \\
\hline Alguma habilidade & 7 & 6,9 \\
\hline Total & $\mathbf{1 0 1}$ & $\mathbf{1 0 0 , 0}$ \\
\hline
\end{tabular}

Também foi questionado para esse grupo, onde aprenderam a Língua de Sinais: dois disseram que foi pela Internet, outros dois de maneira informal na escola ou faculdade, um deles por meio de familiares e/ou amigos, um por meio de disciplina na escola ou faculdade e um com professores e/ou cursos particulares.

Considerando que dentro da UFMG há a disciplina optativa "Fundamentos de Libras", foi feito um levantamento, a fim de analisar a contribuição desta disciplina na formação acadêmica dos estudantes de Medicina da Universidade (Tabelas 2 e 3). Um quarto dos entrevistados não sabia da disciplina e apenas 3 alunos realizaram a matéria. 
Dias AR, et al. Libras na formação médica: possibilidade de quebra da barreira comunicativa.

Tabela 2. Perguntas e respostas sobre a disciplina "Fundamentos de Libras"

\begin{tabular}{l|c|c}
\hline Perguntas e Respostas & Frequência & \% \\
\hline \multicolumn{2}{l|}{$\begin{array}{l}\text { Você sabia que existia a disciplina "Fundamentos de Libras" } \\
\text { como disciplina optativa no currículo da UFMG? }\end{array}$} \\
\hline Sim & 75 & 74,3 \\
\hline Não & 26 & 25,7 \\
\hline Total & $\mathbf{1 0 1}$ & $\mathbf{1 0 0 , 0}$ \\
\hline
\end{tabular}

Tabela 3.Perguntas e respostas sobre a disciplina "Fundamentos de Libras"

\begin{tabular}{l|c|c}
\hline \multicolumn{1}{c|}{ Perguntas e Respostas } & Frequência & \% \\
\hline $\begin{array}{l}\text { Você fez a disciplina optativa "Fundamentos de Libras" } \\
\text { oferecido pela UFMG? }\end{array}$ & 3 & 3,0 \\
\hline Sim & 98 & 97,0 \\
\hline Não & $\mathbf{1 0 1}$ & $\mathbf{1 0 0 , 0}$ \\
\hline Total
\end{tabular}

Outro questionamento feito foi o que esses estudantes, que estão prestes a se tornarem médicos, fariam ao atender um paciente deficiente auditivo que só utiliza a Libras. Mais da metade (53,46\%) respondeu que escreveria, desenharia e/ou faria mímicas, $18,81 \%$ responderam que pediriam ajuda a um intérprete, $12,87 \%$ responderam que falariam lentamente para que o paciente fizesse leitura labial, enquanto $7,92 \%$ responderam que não saberiam o que fazer. Como era esperado, todos do grupo que possuem alguma habilidade em Libras $(6,93 \%)$ responderam que utilizariam a Libras mesmo que de maneira limitada.

Para avaliar qual importância é dada pelo estudante de medicina à comunicação com deficientes auditivos no seu futuro próximo como profissional da saúde, foram feitas duas perguntas, uma quantitativa e outra qualitativa (Tabela 4). Observou-se que a maioria dos alunos $(79,2 \%)$ acredita ser importante saber Libras para a formação médica.

Tabela 4. Perguntas e respostas sobre a importância da Libras para formação médica

\begin{tabular}{l|c|c}
\hline $\begin{array}{l}\text { Perguntas e } \\
\text { Respostas }\end{array}$ & Frequência & $\mathbf{\%}$ \\
\hline \multicolumn{3}{|l}{$\begin{array}{l}\text { Você acredita ser importante para a formação médica saber } \\
\text { se comunicar com deficientes auditivos através da Libras? }\end{array}$} \\
\hline Sim & 80 & 79,2 \\
\hline Não & 21 & 20,8 \\
\hline Total & $\mathbf{1 0 1}$ & $\mathbf{1 0 0 , 0}$ \\
\hline
\end{tabular}

Baseado nas respostas da Tabela 4 e da pergunta discursiva "Por que você acredita ou não acredita ser importante para a formação médica saber se comunicar com deficientes auditivos por meio da Libras?", obteve-se como resultado três perfis entre os estudantes de Medicina do $12^{\circ}$ período da UFMG, a saber: 1) Acredita ser importante e essencial saber Libras (75\%), acredita ser interessante, mas não essencial saber Libras (7\%), e aquele que não acredita ser importante saber Libras para a formação médica (16\%). Dois alunos $(2 \%)$ não responderam à questão.

\section{DISCUSSÃO}

As recomendações do Ministério da Saúde, cujo paroxismo foi marcado pela instituição da Política Nacional de Atenção à Saúde Auditiva ${ }^{14}$, para a atenção à pessoa portadora de deficiência envolvem esforços intersetoriais. Nessa perspectiva, é designado ao Ministério da Educação o estabelecimento de parcerias que viabilizem o alcance dos objetivos preconizados. Assim, em conformidade a este estudo, é pertinente ressaltar a seguinte atribuição: “ $a$ reavaliação e a adequação de currículos, metodologias e material didático de formação de profissionais na área da Saúde, visando ao atendimento das diretrizes fixadas nesta politica"15.

Consoante ao que foi observado nesta pesquisa, no entanto, nota-se que a maioria dos médicos recémformados pela instituição UFMG ( $\mathrm{n}=95)$ não conseguem se comunicar com surdos por meio da Libras, enquanto uma pequena parcela $(n=7)$ aponta ter alguma habilidade. Ademais, faz-se necessário salientar a presença de outro fator agravante: a heterogeneidade existente entre os indivíduos com deficiência auditiva, como o grau de audição, formas de comunicação e a linguagem adotada ${ }^{16}$.

A condição de surdez pode ser abordada sob duas perspectivas: 1) Clínica-patológica, na qual a surdez é vista como uma "deficiência" em relação à comunidade "ouvinte", colocando os sujeitos surdos em desvantagem, se comparados à maioria da população ${ }^{17}$, e 2) Sócioantropológica, na qual a surdez é vista como uma identidade cultural e linguística ${ }^{17,18}$. Fundamentado nisso, observa-se, no domínio científico, uma prevalência de estudos cuja abrangência se limita à patologia. Assim, discussões que fomentem a análise da condição do paciente surdo nos serviços de atenção à saúde são necessárias, a fim de aprofundar o debate já existente.

Desde a década de 60, quando teve início o processo de formulação de um conceito de deficiência, há uma tendência crescente à conscientização de questões voltadas para esta temática ${ }^{19}$. À vista disso, observa-se que o presente estudo vem corroborar esses dados, em que, aproximadamente, $75 \%$ dos entrevistados acreditam ser importante e essencial saber Libras, uma vez que a comunicação é uma ferramenta importante na prática médica e atua de forma a incluir socialmente a comunidade surda. Aliás, acreditam, também, que a presença de 
intérprete ou uso da escrita atrapalharia a consolidação de uma relação médico-paciente efetiva.

Além disso, tanto no Brasil, como nos EUA, é observada a inconstância de pacientes com deficiência auditiva nos atendimentos em saúde. Segundo estudos, muitos pacientes surdos frequentemente acham o sistema de saúde americano inacessível devido às barreiras de comunicação $^{12}$. Já no Brasil, esses pacientes utilizam o sistema de saúde de modo diferente dos pacientes ouvintes e relatam dificuldades representadas por medo, desconfiança e frustração ${ }^{1}$, assim como os pacientes surdos americanos ${ }^{20}$. A consequência, então, é buscarem assistência médica com menos frequência ${ }^{1}$.

Em conformidade a isso, devido à barreira de comunicação existente, muitas pessoas surdas são incapazes de estabelecer uma forte relação com os seus prestadores de cuidados primários. Assim, isso frequentemente resulta em uma compreensão inadequada do manejo da doença e da adesão ao tratamento. Como consequência disso, como sugerido por evidências anedóticas, indivíduos surdos são mais propensos a recorrer à sala de emergência e serviços de atendimento em urgência para questões ambulatoriais, que por sua vez podem ser acompanhadas pela Atenção Primária à Saúde ${ }^{6,7,21}$.

Estudos americanos apontam que pouca atenção é dada às habilidades comunicativas dos estudantes de medicina com pacientes que apresentam alguma dificuldade auditiva $^{3}$. Nesse sentido, acredita-se que tais circunstâncias são também claramente cabíveis aos cenários das escolas de medicina brasileiras. Concordante a isso, como notado neste estudo, cerca de $8 \%$ dos entrevistados não saberiam o que fazer durante uma consulta com um paciente surdo; enquanto $12,7 \%$ falariam lentamente para que aquele pudesse fazer leitura labial. No entanto, de acordo com a National Associantion of the Deaf isto não é recomendado, uma vez que muitos fatores podem prejudicar tal habilidade, como ansiedade e medicamentos ${ }^{21}$.

Assim, nota-se uma escassez na literatura voltada ao preparo de estudantes de medicina no atendimento de pacientes com perda auditiva, e, ainda, pouco se sabe sobre como é a formação médica em relação a esse acolhimento, sobretudo após a reformulação curricular do curso de medicina. Dessa forma, identificar deficiências comunicacionais na preparação de médicos recémformados da Universidade Federal de Minas Gerais e quais são suas impressões em relação a essa temática deve ser o início para mudanças nesse contexto, a fim de fomentar uma discussão cuja abordagem visa garantir a esses pacientes um estado de bem-estar físico, mental e social adequados.

$\mathrm{Na}$ realidade, apesar do conhecimento de Libras ser um diferencial ou uma adição importante ao médico para a construção de uma relação médico-paciente com o deficiente auditivo, nota-se, ainda, neste estudo a premissa de que o currículo médico por si só já é bastante extenso e exaustivo para que outras disciplinas, como a Libras, sejam acrescentadas na grade curricular. Neste contexto, pode-se verificar que 22,8\% dos entrevistados, Perfil 2 (acreditam ser importante, mas não essencial saber Libras) e Perfil 3 (Não acreditam ser importante saber Libras), acreditam que Libras não é imprescindível na formação médica, justificando que o cuidado, a atenção, a disponibilidade e a empatia possibilitam a comunicação.

\section{CONCLUSÃO}

A partir dos resultados do presente estudo, comprova-se que não há um desenvolvimento efetivo das habilidades de comunicação do aluno de Medicina, uma vez que a grande maioria dos estudantes prestes a se formar não sabe se comunicar com uma parcela da população: os surdos. Esta condição confirma a existência de uma barreira comunicativa entre esses novos médicos e os pacientes que usam Libras, o que dificulta o estabelecimento da relação médico-paciente e, por conseguinte, gera frustração e infrequência do paciente na assistência à saúde. Portanto, tal estudo sinaliza para a necessidade de novas pesquisas que fomentem o debate acerca dessa barreira, a compreensão do surdo em um âmbito social e cultural, a compreensão das condições atuais do surdo nos serviços de atenção à saúde, além de conscientizar que o conhecimento de Libras é importante para gerar uma assistência à saúde humanizada, centrada no paciente com deficiência auditiva. Atender à demanda dos pacientes de forma plena é dever de todos os profissionais que lutam para uma sociedade inclusiva.

AGRADECIMENTOS: Este estudo foi apoiado pelo Centro de Graduação (CEGRAD) da UFMG. Dessa forma, os autores desse artigo agradecem todos os funcionários do CEGRAD que de alguma forma contribuíram para a execução desse trabalho. Ademais, agradecemos a Professora Alamanda Kfoury Pereira, coordenadora do colegiado do curso de Medicina da UFMG, pela prontidão em ajudar e facilitar os meios para que o trabalho fosse efetivado. Por fim, um agradecimento especial a todos os alunos que tiveram interesse em participar da pesquisa.

\section{REFERÊNCIAS}

1. Chaveiro N, Porto CC, Barbosa MA. Relação do paciente surdo com o médico. Rev Bras Otorrinolaringol. 2009;75(1):147-50. doi: http://dx.doi.org/10.1590/S0034-72992009000100023.

2. Secretaria de Direitos Humanos da Presidência da República (SDH/PR), Secretaria Nacional de Promoção dos Direitos da Pessoa com Deficiência (SNPD), Coordenação-Geral do
Sistema de Informações sobre a Pessoa com Deficiência. Cartilha do Censo 2010 - Pessoas com deficiência. Brasília: SDH-PR/SNPD; 2012. Disponível em: http:// www.pessoacomdeficiencia.gov.br/app/sites/default/ files/publicacoes/cartilha-censo-2010-pessoas-comdeficienciareduzido.pdf.

3. Barnett MDS. Communication with deaf and hard-ofhearing people: a guide for medical education. Acad Med. 
Dias AR, et al. Libras na formação médica: possibilidade de quebra da barreira comunicativa.

2002;77(7):694-700. Available from: http://journals.lww.com/ academicmedicine/Fulltext/2002/07000/Communication_ with_Deaf_and_Hard_of_hearing.9.aspx.

4. Brasil. Ministério da Justiça. Secretaria Nacional de Justiça. Departamento de Justiça, Classificação, títulos e qualificação. A classificação indicativa na língua brasileira de sinais. Brasília; 2009. Disponível em: http://www.justica.gov.br/ seus-direitos/classificacao/classificacaolinguasinais.pdf.

5. Mcaleer M. Communicating effectively with deaf patients. Nurs Stand. 2006;20(19):51-4. doi: 10.7748/ ns2006.01.20.19.51.c4044.

6. Silva RNA, Silva SR, Filha FSSC, Silva FL, Vilanova JM. Assistência ao surdo na atenção primária: concepções de profissionais. J Manag Prim Health Care. 2015;6(2):189-204. Disponível em: http://www.jmphc.com.br/saude-publica/ index.php/jmphc/article/view/266/Assistencia\%20ao\%20 surdo.

7. Chaveiro N, Barbosa MA, Porto CC, Munari DB, Medeiros $\mathrm{M}$, Duarte SBR. Atendimento à pessoa surda que utiliza a língua de sinais, na perspectiva do profissional de saúde. Cogitare Enferm. 2010;15(4):639-45 doi: http://revistas.ufpr. br/cogitare/article/viewFile/20359/13520.

8. Brasil. Presidência da República. Casa Civil. Subchefia para Assuntos Jurídicos. Lei no 10.436, de 24 de abril de 2002. Dispõe sobre a Língua Brasileira de Sinais - Libras - e dá outras providências. Brasília; 2002. Disponível em: http:// www.planalto.gov.br/ccivil 03/leis/2002/L10436.htm.

9. Brasil. Presidência da República. Casa Civil. Subchefia para Assuntos Jurídicos. Decreto ${ }^{0} 5.626$, de 22 de dezembro de 2005. Regulamenta a Lei $\mathrm{n}^{\circ} 10.436$, de 24 de abril de 2002, que dispõe sobre a Língua Brasileira de Sinais - Libras, e o art. 18 da Lei ${ }^{\circ} 10.098$, de 19 de dezembro de 2000. Brasília; 2005. Disponível em: http://www.planalto.gov.br/ ccivil_03/_ato2004-2006/2005/decreto/d5626.htm.

10. Brasil. Ministério da Saúde. Secretaria de Atenção à Saúde. Departamento de Ações Programáticas Estratégicas A pessoa com deficiência e o Sistema Único de Saúde. Brasília; 2006. Disponível em: http://bvsms.saude.gov.br/bvs/ publicacoes/07_0327_M.pdf.

11. Tedesco JR, Junges JR. Desafios da prática do acolhimento de surdos na atenção primária. Cad Saúde Pública. 2013;29(8):1685-9. http://dx.doi.org/10.1590/0102$311 \mathrm{X} 00166212$.

Artigo recebido em: 28.04.17

Artigo aceito em: 21.08.17
12. Brown L, Hughes-Bell A, McDuffie AW. Caring for patients who are deaf or hard of hearing Heather. J Am Acad Phys. 2015;28(12):50-5. doi: 10.1097/01. JAA.0000473363.92597.91.

13. Levino DA, Souza EB, Cardoso PC, Silva AC, Carvalho AETM. Libras na graduação médica: o despertar para uma nova língua. Rev Bras Educ Med. 2013;37(2):291-7. Disponível em: http://www.scielo.br/pdf/rbem/v37n2/18.pdf.

14. Brasil. Ministério da Saúde. Portaria $n^{\circ} 2.073$, de 28 de setembro de 2004. Institui a Política Nacional de Atenção à Saúde Auditiva. Disponível em: http://bvsms.saude.gov.br/ bvs/saudelegis/gm/2004/prt2073_28_09_2004.html.

15. Política nacional de saúde da pessoa portadora de deficiência. Diário Oficial da União, n.109, Seção1, 10 jun. 2002. p.25. Disponível em: http://pesquisa.in.gov.br/imprensa/servlet/NP DFViewer?jornal $=1 \&$ pagina $=25 \&$ data $=10 / 06 / 2002 \&$ captch afield $=$ firistAccess.

16. Gesueli ZM. Lingua(gem) e identidade: a surdez em questão. Educ Soc (Campinas). 2006;27(94):277-92. doi: http://dx.doi. org/10.1590/S0101-73302006000100013.

17. Alpendre EV. Concepções sobre surdez e linguagem e o aprendizado de leitura [dissertação]. 2008. Curitiba: Programa de Desenvolvimento Educacional (PDE); 2008. Disponível em: http://www.diaadiaeducacao.pr.gov.br/portals/pde/ arquivos/417-2.pdf

18. Costa MFM. Análise da utilização da atenção primária à saúde pelo usuário surdo sob a perspectiva do profissional de enfermagem: estudo descritivo nas unidades de saúde da Ceilândia - DF [Bacharelado]. Ceilândia, DF: Universidade de Brasília, Faculdade de Ceilândia; 2013. Disponível em: http://bdm.unb.br/bitstream/10483/6916/1/2013 MarianaFerreiraMarquesCosta.pdf.

19. Brasil. Ministério da Saúde. Secretaria de Atenção à Saúde. Política Nacional de Saúde da Pessoa Portadora de Deficiência, Série E. Legislação em saúde. Brasília, DF; 2008. Disponível em: http://bvsms.saude.gov.br/bvs/publicacoes/ politica_nacional_saude_pessoa_deficiencia.pdf.

20. Steinberg AG, Barnett S, Meador HE, Wiggins EA, Zazove P. Health care system accessibility experiences and perceptions of deaf people. J Gen Intern Med. 2006;21:260-6. DOI: 10.1111/j.1525-1497.2006.00340_1.x

21. National Association of the Deaf. Position statement on health care access for deaf patients. Available from: https://www. nad.org/about-us/position-statements/position-statement-onhealth-care-access-for-deaf-patients. 